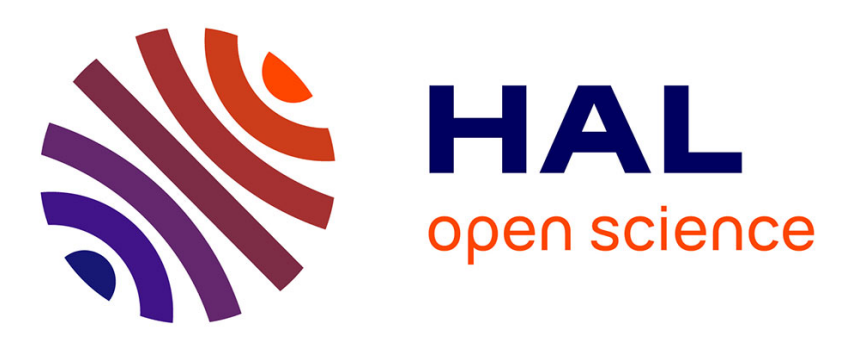

\title{
Nonlinear plasmonic nanohybrids as probes for multimodal cell imaging and potential phototherapeutic agents
}

Maxime Boksebeld, Vasyl Kilin, Rachael Taitt, Luigi Bonacina, Alain Geloen, Vladimir Lysenko, Yann Chevolot, Virginie Monnier

\section{To cite this version:}

Maxime Boksebeld, Vasyl Kilin, Rachael Taitt, Luigi Bonacina, Alain Geloen, et al.. Nonlinear plasmonic nanohybrids as probes for multimodal cell imaging and potential phototherapeutic agents. Biomedical Physics \& Engineering Express, 2019, 5 (2), pp.025039. 10.1088/2057-1976/ab0232 . hal02270136

\section{HAL Id: hal-02270136 \\ https://hal.science/hal-02270136}

Submitted on 10 Nov 2020

HAL is a multi-disciplinary open access archive for the deposit and dissemination of scientific research documents, whether they are published or not. The documents may come from teaching and research institutions in France or abroad, or from public or private research centers.
L'archive ouverte pluridisciplinaire HAL, est destinée au dépôt et à la diffusion de documents scientifiques de niveau recherche, publiés ou non, émanant des établissements d'enseignement et de recherche français ou étrangers, des laboratoires publics ou privés. 


\title{
Nonlinear plasmonic nanohybrids as probes for multimodal cell imaging and potential phototherapeutic agents
}

To cite this article before publication: Maxime Boksebeld et al 2019 Biomed. Phys. Eng. Express in press https://doi.org/10.1088/20571976/ab0232

\author{
Manuscript version: Accepted Manuscript \\ Accepted Manuscript is "the version of the article accepted for publication including all changes made as a result of the peer review process, \\ and which may also include the addition to the article by IOP Publishing of a header, an article ID, a cover sheet and/or an 'Accepted \\ Manuscript' watermark, but excluding any other editing, typesetting or other changes made by IOP Publishing and/or its licensors" \\ This Accepted Manuscript is (c) 2018 IOP Publishing Ltd
}

During the embargo period (the 12 month period from the publication of the Version of Record of this article), the Accepted Manuscript is fully protected by copyright and cannot be reused or reposted elsewhere.

As the Version of Record of this article is going to be / has been published on a subscription basis, this Accepted Manuscript is available for reuse under a CC BY-NC-ND 3.0 licence after the 12 month embargo period.

After the embargo period, everyone is permitted to use copy and redistribute this article for non-commercial purposes only, provided that they adhere to all the terms of the licence https://creativecommons.org/licences/by-nc-nd/3.0

Although reasonable endeavours have been taken to obtain all necessary permissions from third parties to include their copyrighted content within this article, their full citation and copyright line may not be present in this Accepted Manuscript version. Before using any content from this article, please refer to the Version of Record on IOPscience once published for full citation and copyright details, as permissions will likely be required. All third party content is fully copyright protected, unless specifically stated otherwise in the figure caption in the Version of Record.

View the article online for updates and enhancements. 
Nonlinear plasmonic nanohybrids as probes for multimodal cell imaging and potential phototherapeutic agents

Maxime Boksebeld ${ }^{1}$, Vasyl Kilin ${ }^{2}$, Rachael Taitt ${ }^{1}$, Luigi Bonacina ${ }^{2}$, Alain Géloën ${ }^{3}$, Vladimir Lysenko $^{4}$, Yann Chevolot ${ }^{1}$, Virginie Monnier ${ }^{1 *}$

${ }^{1}$ Université de Lyon, Ecole Centrale de Lyon, UMR CNRS 5270, Institut des Nanotechnologies de Lyon, Ecully, F-69130, France.

2 Université de Genève, GAP Biophotonics, 22 Chemin de Pinchat, CH-1211 Geneva, Switzerland.

${ }^{3}$ Université de Lyon, CARMEN INSERM U1060, INSA Lyon, F-69621 Villeurbanne, France.

${ }^{4}$ Université de Lyon, INSA Lyon, CNRS, UMR CNRS 5270, Institut des Nanotechnologies de Lyon, Villeurbanne, F-69621, France.

*E-mail : virginie.monnier@ec-1yon.fr

Keywords: silicon carbide, multiphoton imaging, gold nanorods, photothermal effect, cancer cells.

\section{Abstract}

Silicon carbide $(\mathrm{SiC})$ nanoparticles were coated with gold nanorods to prepare nonlinear plasmonic nanohybrids. Their structural properties were evaluated by Transmission Electron Microscopy. Nonlinear optical properties of the two components (second harmonic generation for SiC nanoparticles, two-photon luminescence for gold nanorods) were simultaneously found into nanohybrids and spatially colocalized. Photothermal effect was observed for nanohybrids. The cytotoxicity of nanoparticles, nanorods and nanohybrids towards healthy and cancer cell lines was then evaluated. SiC nanoparticles and nanohybrids showed no cytotoxicity for healthy 
cells while gold nanorods were found to exhibit an increasing toxicity with increasing concentrations, which was related to the presence of CTAB surfactant on their surface. Finally, nanohybrids exhibit toxicity for cancer cells and this effect was increased under laser irradiation at $808 \mathrm{~nm}$, which matches the plasmon resonance of gold nanorods.

\section{Introduction}

The World Health Organization recently reported that cancer is the second leading cause of death worldwide. ${ }^{[1]}$ Therefore, tremendous efforts have been devoted to novel cancer diagnostic and therapeutic approaches. Among other, tumor cells apoptosis can be triggered by the local increase of the temperature. Such local heating can be achieved by photothermia, the conversion of light into heat. Gold nanoparticles have attracted attention as they can be easily synthesized, their surface can be engineered for tumor cell targeting, and their optical properties can be tuned by controlling their size and shape. ${ }^{[2]}$ Light absorption near the plasmon band resonance can be up to 4-6 times higher than organic dyes. ${ }^{[3,4]}$ Moreover, upon light absorption, the incoming energy is transformed into heat and bubbles are formed leading to cellular apoptosis due to thermal and mechanical stress. ${ }^{[5]}$ However, gold/nanospheres suffer from an absorption band located at $520 \mathrm{~nm}$, far from the biological transparency window which is located in the near infrared (NIR) spectral region (650-1050 nm), low heating efficiency and low cavitation bubbles formation threshold. ${ }^{[6]}$ To overcome these shortcomings, efforts have been made to develop gold nanorods, nanoshells or nanoclusters of different shapes (nanostars, nanocages) for which the plasmon resonance can be shifted toward the NIR with a narrow and intense absorption band. In particular, for gold nanorods, the variation of aspect ratio (length to diameter ratio) allows a fine tuning of plasmon resonance in this spectral range. Besides, El Fayed et al demonstrated using Mie based calculations that gold nanorods absorption coefficient in the NIR region is higher than for gold nanoshells. ${ }^{[7]}$ Finally, the gold nanorods cytotoxicity seems to be related to the presence of hexadecyltrimethylammonium bromide 
(CTAB) which is commonly used for their synthesis. ${ }^{[2]}$ Alternative surfactant or capping of the nanorods with a polymeric layer has been proposed as possible way to overcome this toxicity. ${ }^{[8]}$ Another advantage of gold nanostructures such as gold nanorods is that they can exhibit twophoton luminescence (TPL), which allows cell imaging under excitation in the NIR region. ${ }^{[9]}$ However, the signal is generally broad and not specific as many other biological components, such as proteins and co-factors possess overlapping emission bands. ${ }^{[10]}$ Thus, sensitive detection and high contrast imaging can be reached only if gold nanorods are coupled to other nanostructures. Nanoparticles based on non-centrosymmetric crystalline materials (also called harmonic nanoparticles) exhibit an intense and sharp second harmonic generation (SHG) signal in a wide range of excitation wavelengths, that can be used for cell imaging and tracking ${ }^{[11,12]}$. Moreover, these materials generally exhibit low cytotoxicity at the nanoscale ${ }^{[13]}$. In particular, silicon carbide $(\mathrm{SiC})$ nanoparticles were recently used for cancer cells targeting ${ }^{[14]}$.

Coupling gold nanorods to other nanostructures was mainly achieved through Coulombic interactions. Recently, gold nanorods were immobilized on silica-coated iron oxide nanoparticles by polyethylenimine/poly(styrenesulfonate) ${ }^{[15]}$ and CTAB/silica ${ }^{[16]}$ interactions allowing for the fabrication of multifunctional nanohybrids featuring photothermal properties and magnetic properties. Direct assembly between iron oxide nanoparticles and gold nanorods was also achieved through polydopamine/disulphide-modified poly(2-dimethyl amino)ethyl methacrylate interaction ${ }^{[17]}$. In this case, the objective was to combine photothermal/gene therapy using plasmid DNA. Gold nanorods were also coupled to upconversion nanoparticles via poly-L-lysine/silica ${ }^{[18]}$ and chitosan/aminosilane ${ }^{[19]}$ interactions for phototherapeutic applications. Polyethyleneglycol (PEG)-based linkers were also used to immobilize gold nanorods onto various kinds of nanoparticles. For instance, gold nanorods were linked to mesoporous silica nanocarriers for light triggered photothermal and photodynamic therapy ${ }^{[20]}$. In another report, Prussian-blue-functionalized lanthanide-ion-doped inorganic nanoparticles 
were coated with gold nanorods using a PEG-thiol linker for targeted photothermal therapy on breast cancer cells ${ }^{[21]}$. Hu et al prepared cellulose-gold nanorods nanohybrids with lipoic acid as a linker and used them for photoacoustic imaging and combined photothermal/gene therapy $[22]$.

This paper is focused on the synthesis of nanohybrids composed of gold nanorods immobilized on a non-centrosymmetric core ( $\mathrm{SiC}$ ) exhibiting SHG signal. Positively-charged gold nanorods were synthesized using the standard CTAB-based method and then simply immobilized by electrostatic self-assembly on the negatively-charged $\mathrm{SiC}$ cores. The nonlinear optical properties (TPL and SHG) and photothermal effect of nanohybrids, gold nanorods and noncentrosymmetric cores were compared. Then, nanoparticles incubated with healthy cells were observed using multiphoton microscopy and their cytotoxicity was investigated. Finally, the phototherapeutic properties of nanoparticles incubated with cancer cells were studied under laser irradiation at $808 \mathrm{~nm}$.

\section{Experimental}

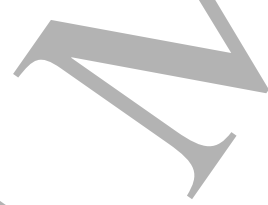

2.1. Materials

SiC-3C nanoparticles were purchased form KM Labs (Ukraine). They were produced by carbothermal reduction of amorphous silica in presence of sucrose and citric acid at $240^{\circ} \mathrm{C}$. Then the obtained powder was heated at $1420^{\circ} \mathrm{C}$ under argon. All other chemicals were obtained from Sigma-Aldrich and used as received. Milli-Q water (18.2 $\mathrm{M} \Omega \mathrm{cm})$ was used in all the preparations.

\subsection{Initial stabilization of $\mathrm{SiC}$ nanoparticles}

The initial powder of $\mathrm{SiC}$ nanoparticles was heated at $600^{\circ} \mathrm{C}$, in air, during $1 \mathrm{~h}$. After cooling, the powder was dispersed at a concentration of $80 \mathrm{mg} \mathrm{mL}^{-1}$ in an aqueous $\mathrm{KOH} 9 \mathrm{M}$ solution and the dispersion was sonicated during $1 \mathrm{~h}$. Then, nanoparticles were washed three times by 
centrifugation (1000g, 1-5 min) and redispersed in water. After redispersion, nanoparticles were let for sedimentation during $24 \mathrm{~h}$. The resulting precipitate was discarded and the supernatant, containing a concentration of around $8 \mathrm{mg} \mathrm{mL}^{-1}$ in $\mathrm{SiC}$ nanoparticles, was kept for functionalization. The resulting nanoparticles suspensions were stable for several days.

\subsection{Synthesis of Au nanorods}

Nanorods were prepared using a previously reported protocol ${ }^{[23]}$. Gold seeds were synthesized by mixing $629 \mu \mathrm{L}$ of aqueous CTAB solution $(150 \mathrm{mM}), 216 \mu \mathrm{L}$ of deionized water and 55.1 $\mu \mathrm{L}$ of aqueous $\mathrm{HAuCl}_{4}$ solution $(4.28 \mathrm{mM})$. Then, $100 \mu \mathrm{L}$ of $\mathrm{NaBH}_{4}$ aqueous solution was added and the obtained solution was left to react during $3 \mathrm{~h}$ at $25^{\circ} \mathrm{C}$. Next, the growth solution was prepared by mixing $9.87 \mathrm{~mL}$ of aqueous CTAB solution $(150 \mathrm{mM}), 2.2 \mathrm{~mL}$ of deionized water and $1.73 \mathrm{~mL}$ of aqueous $\mathrm{HAuCl}_{4}$ solution $(4.28 \mathrm{mM})$. Then, $200 \mu \mathrm{L}$ of an aqueous $\mathrm{AgNO}_{3}$ solution $(7.4 \mathrm{mM})$ were added, to obtain nanorods with an aspect ratio of 4.4 . The obtained solution was stirred slowly during $2 \mathrm{~min}$ and $1 \mathrm{~mL}$ of aqueous solution of ascorbic acid (8.18 $\mathrm{mM}$ ) was then added. After a slow stirring of $1 \mathrm{~min}, 25 \mu \mathrm{L}$ of the previously prepared gold seed suspension was added. The solution was stirred for $1 \mathrm{~min}$ and let to react, at $30^{\circ} \mathrm{C}$, overnight. Centrifugation at $6700 \mathrm{~g}$ during $5 \mathrm{~min}$ was used to stop the reaction and remove reactants and by-products from nanorod suspension after reaction. Finally, a shape-selective purification was applied to eliminate nanospheres from nanorods suspensions according to a previously reported procedure. ${ }^{[24]}$

\subsection{Elaboration of SiC@Au nanohybrids}

$500 \mu \mathrm{L}$ of $\mathrm{Au}$ nanorods suspension $(100 \mathrm{mg} / \mathrm{L}$ in water) were centrifuged at $6700 \mathrm{~g}$ during 6 min for three times to eliminate the excess of CTAB. They were redispersed in $500 \mu \mathrm{L}$ of water. Then $30 \mu \mathrm{L}$ or $120 \mu \mathrm{L}$ of $\mathrm{SiC}$ nanoparticles suspension $(2.67 \mathrm{~g} / \mathrm{L}$ in water $)$ were added to the $\mathrm{Au}$ nanorods suspension. The mixture was stirred at $500 \mathrm{rpm}$ overnight. Finally, the nanohybrids suspension was centrifuged at $6700 \mathrm{~g}$ during 2 min and redispersed in $500 \mu \mathrm{L}$ of 
water. This short centrifugation time was necessary to keep free nanorods in the supernatant. Then, two populations of nanohybrids were identified: a first population that sedimented within a few minutes and a second one that remained in suspension for several days. Only the second population (in the supernatant) was kept for further measurements after natural sedimentation of the first one.

2.5. Cell incubation and irradiation with nanoparticles and nanohybrids

Cell cultures of 3T3-L1 mouse fibroblasts (American Type Culture Collection, Manassas, VA, USA) and human hepatocarcinoma-derived HuH7 cells (European Collection of Cell Cultures, Salisbury, UK) were initially grown in Dulbecco's modified Eagle's medium (DMEM) containing $4.5 \mathrm{~g} \mathrm{~L}^{-1}$ glucose supplemented with $10 \%$ newborn calf serum (American Type Culture Collection, Manassas, VA, USA), $100 \mathrm{IU}$ penicillin, and $100 \mu \mathrm{g}$ streptomycin at $37^{\circ} \mathrm{C}$ in a water-saturated atmosphere with $5 \% \mathrm{CO}_{2}$, in a Heraeus incubator. A 96-well microplate with wells of $8 \mathrm{~mm}$ in diameter was used for incubation. Cells were seeded at 2500 cells per well. Nanoparticles were introduced at concentrations ranging from 1.25 to $20 \mu \mathrm{g} \mathrm{mL}^{-1}$. After $2 \mathrm{~h}$ of incubation with $\mathrm{HuH7}$ cells, half of the wells were irradiated with a continuous-wave Newport laser emitting at a wavelength of $808 \mathrm{~nm}$ during 12 min using an optical fiber of 200 $\mu \mathrm{m}$ in diameter and a numerical aperture of 0.22 . The measured surface power at the apex of the fiber was $40 \mathrm{~mW} \mathrm{~cm}^{-2}$. An empty microplate was put on the top of the microplate containing cells incubated with nanoparticles. Then the optical fiber of the laser beam was put inside the wells of the empty microplate for irradiation. During irradiation, the microplate was kept under a temperature of $37^{\circ} \mathrm{C}$.

2.6. Photothermal properties evaluation

Drops of $3 \mu \mathrm{L}$ of nanoparticles suspensions were deposited on a microstructured hydrophobic glass slide. Then the drops were successively irradiated with the $808 \mathrm{~nm}$ continuous-wave laser 
via the optical fiber. The heat generation was recorded with a ThermoVision A20M infrared camera from Flir Systems in a top view of the glass slide.

\subsection{Toxicity assay}

Cell proliferation and/or survival was monitored with the xCELLigence Real-time Cell Analyser (RTCA) System (ACEA Biosciences, Inc., San Diego, USA), which allows label-free and non-destructive monitoring changes of cell number, viability, morphology and quality of cell attachment by measurement of cell to electrode responses of cells seeded in E96-well plates manufactured with integrated microelectronic sensor arrays. RTCA system measures real-time impedance variations that are then converted in cell surface occupancy, i.e. cell index, taking into account cell number, cell size, and adhesion force. When cell index reaches a sufficient value (typically between 1 and 2), nanoparticles are introduced and incubated with cells during $24 \mathrm{~h}$ using the protocol detailed in the previous section. During this $24 \mathrm{~h}$ duration, the colloidal stability of nanoparticles suspensions was ensured. Cell indexes are normalized at the introduction of nanoparticles in order to facilitate the comparison between the different conditions. Then nanoparticles are removed by replacing the cell culture medium by a fresh one. The impedance measurements are maintained during $24 \mathrm{~h}$ in order to study the influence of washing.

\subsection{Multiphoton imaging}

Nanoparticles drop casted on a substrate or in fixed cells were observed with a Nikon multiphoton inverted microscope (A1R-MP) coupled to a Mai-Tai tunable Ti:sapphire oscillator (Spectra-Physics; $100 \mathrm{fs}, 80 \mathrm{MHz}, 700-1000 \mathrm{~nm}$ ). A plan apochromat 20× waterimmersion objective with a 0.75 numerical aperture was used to focus the excitation laser at $790 \mathrm{~nm}$ and epi-collect the two-photon luminescence (TPL) and second harmonic generation (SHG) emission. The collected signals were processed by non-descanned detectors with using band-pass filters (SemRock) of 395/11 nm for SHG and 607/70 nm for two-photon 
luminescence. Alternatively the epi-collected signal were sent through a fiber to a spectral detection unit allowing the simultaneous detection of up to 32 independent channels.

\subsection{Other characterization techniques}

Zeta potential was evaluated using a Zetasizer apparatus (Malvern Instruments). UV-Vis absorption spectra were collected in a quartz cell with $1.0 \mathrm{~cm}$ path length using a SAFAS-UV mc2 double-beam spectrophotometer. TEM images were realized with a JEOL 2100HT microscope working at $200 \mathrm{kV}$. For TEM studies, $2 \mu \mathrm{L}$ of the diluted dispersion of nanoparticles was deposited onto a carbon holey grid (Ted Pella, Inc.). Images were analyzed with ImageJ 1.46r software.

\section{Results and discussion}

\subsection{Structural properties of SiC@Au nanohybrids}

Gold nanorods were first characterized using UV-Vis absorption spectroscopy and TEM (Figure 1).
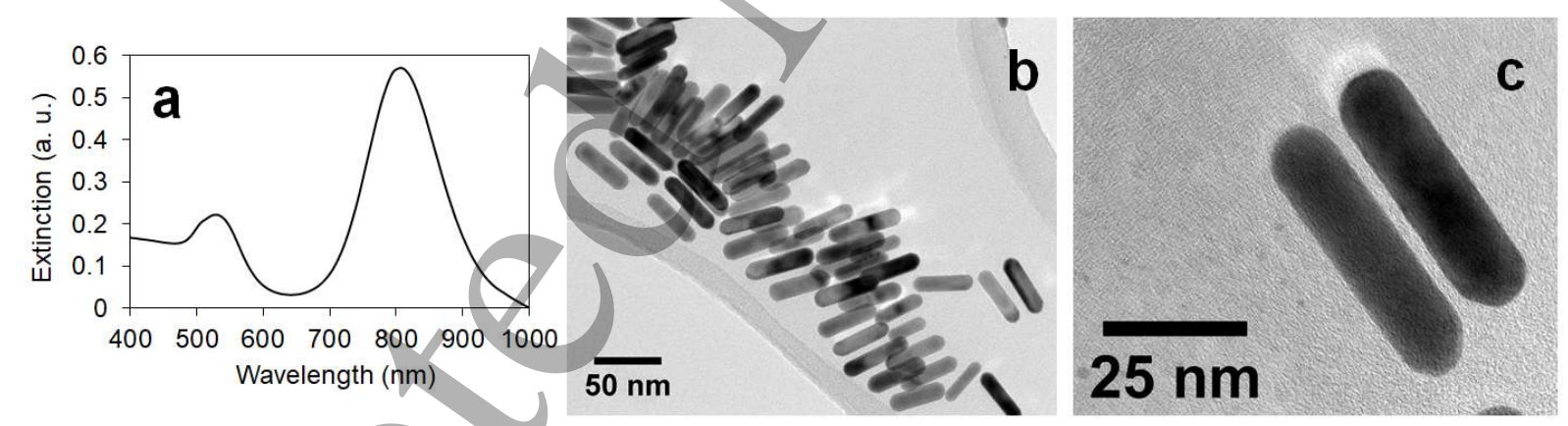

Figure 1. Extinction spectrum (a) and TEM images (b and c) of Au nanorods.

$\mathrm{Au}$ nanorods exhibited a high intensity absorption band centered at $808 \mathrm{~nm}$ and a low intensity absorption band around $529 \mathrm{~nm}$ (Figure 1a). These two bands can be attributed to the longitudinal plasmon resonance mode of nanorods and to a combination of transverse plasmon resonance mode of nanorods and plasmon resonance of remaining nanospheres (less than $7 \%$ 
after shape-selective purification ${ }^{[24]}$ ), respectively. This was confirmed by TEM images (Figures $1 \mathrm{~b}$ and $1 \mathrm{c}$ ) in which a mean length of $47.6 \pm 3.9 \mathrm{~nm}$ and a mean diameter of $12.3 \pm 1.2$ $\mathrm{nm}$ were determined (aspect ratio: 3.9). This aspect ratio is in agreement with the position of the measured longitudinal plasmon resonance band of gold nanorods according to previous works ${ }^{[25,26]}$. As shown in Supporting Information (Figure S2), SiC nanoparticles exhibited a zeta potential around $-50 \mathrm{mV}$. After their synthesis, Au nanorods were coated with CTAB, a positively charged tensio-active molecule, thus they naturally exhibited a positive zeta potential of $+55 \mathrm{mV}$. Due to the highly negative value of zeta potential for SiC nanoparticles, SiC@Au nanohybrids were elaborated through the ionic interaction between the oppositely charged surfaces of SiC and as-synthesized Au nanorods coated with CTAB. Figure 2 showed TEM images of initial SiC nanoparticles (Figure 2a) compared to SiC@Au nanohybrids (Figure 2b).

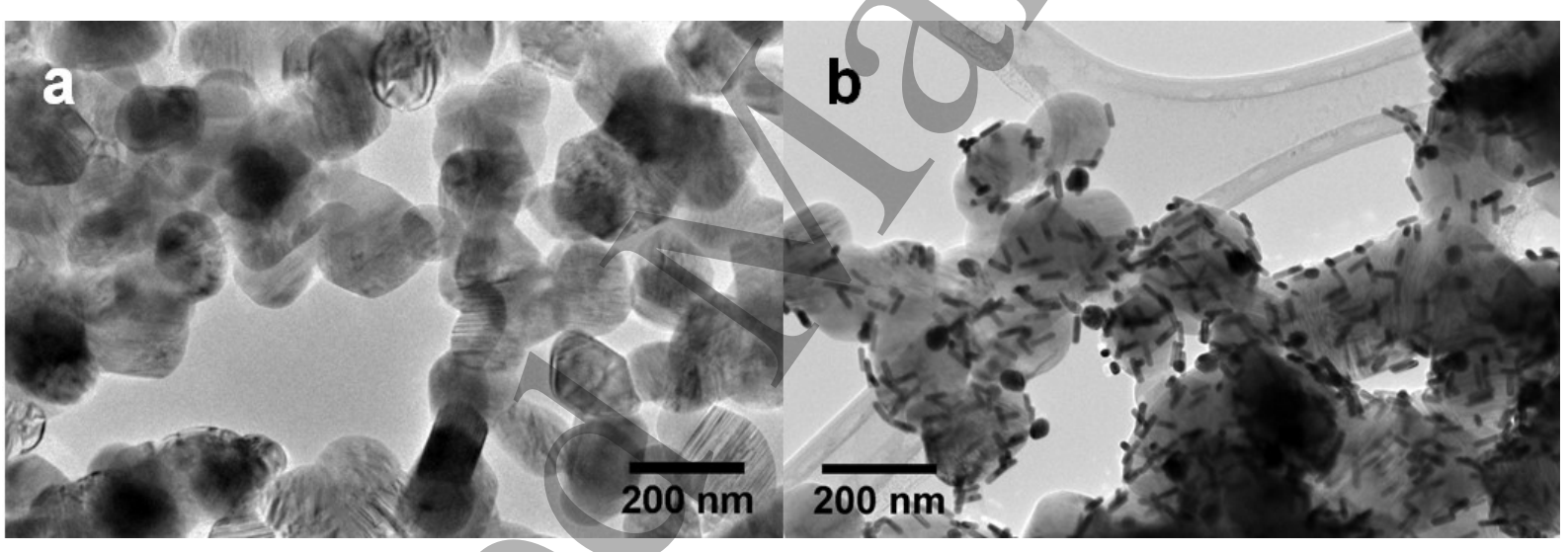

Figure 2. TEM images of SiC nanoparticles (a) and SiC@Au nanohybrids (b).

As shown in Figure 2a, SiC nanoparticles exhibited a diameter, ranging from 80 to $220 \mathrm{~nm}$, centered around $150 \mathrm{~nm}$. The success of Au nanorods immobilization onto $\mathrm{SiC}$ nanoparticles was evidenced by dark spots (Figure 2b) corresponding to Au nanorods onto SiC@Au nanohybrids. No free Au nanorods were observed. The clustering effect observed on TEM images was mainly due to the drying of aqueous suspensions of nanoparticles onto hydrophobic 
TEM grids (coated with a carbon membrane). It did not reflect the behaviour of nanoparticles in suspension, as colloidal stability was ensured for several days.

\subsection{Nonlinear optical properties of SiC@Au}

Then, the nonlinear optical properties of $\mathrm{Au}$ nanorods, SiC nanoparticles and $\mathrm{SiC} @ \mathrm{Au}$ nanohybrids were studied. Figure 3 shows the nonlinear optical responses from Au nanorods, SiC nanoparticles and SiC@Au nanohybrids under 820 nm excitation.

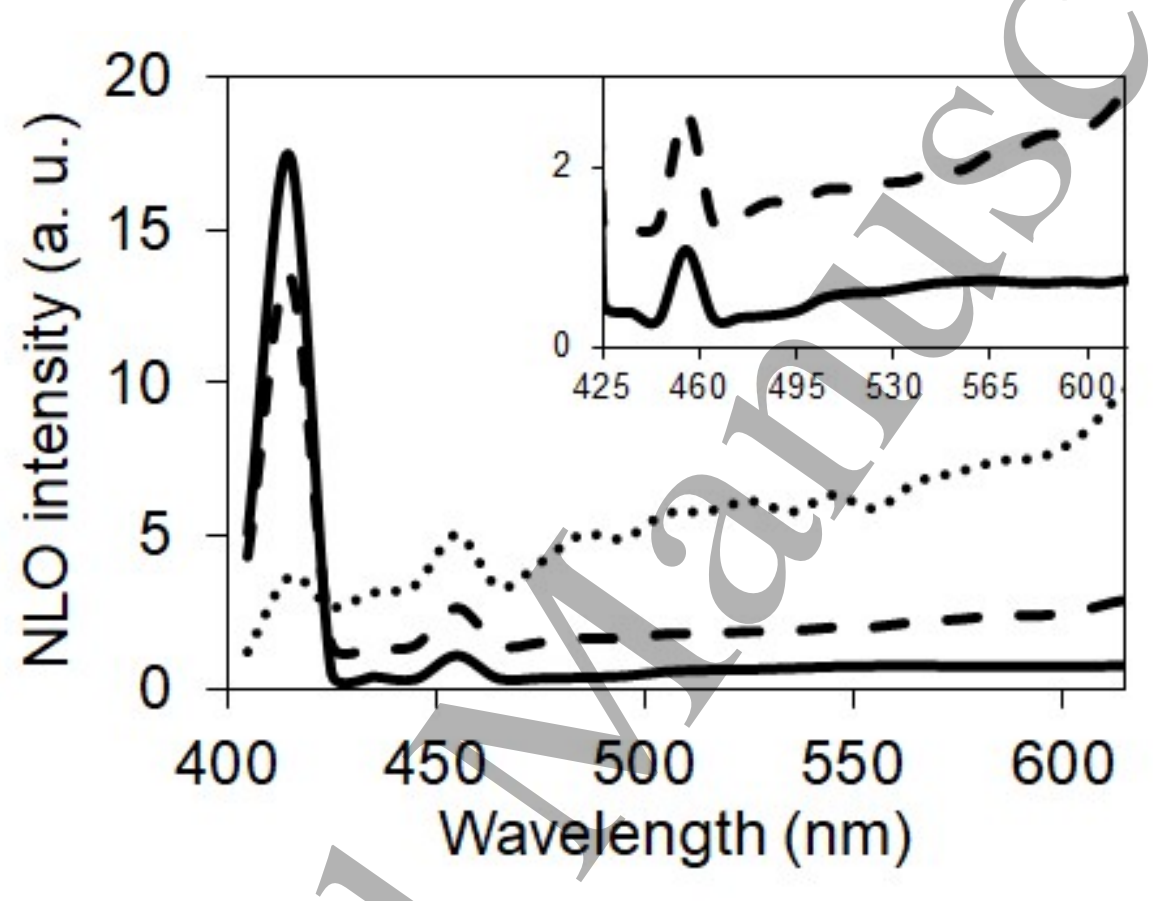

Figure 3. Nonlinear optical (NLO) response from $\mathrm{Au}$ nanorods (dot line), SiC nanoparticles (solid line) and SiC@Au nanohybrids (dashed line) under 820 nm excitation. Insert: magnification on the $425-615 \mathrm{~nm}$ region.

On one hand, it reveals a strong SHG response at $410 \mathrm{~nm}$ for SiC nanoparticles and SiC@ $\mathrm{Au}$ nanohybrids while this peak is absent for Au nanorods. The lower SHG peak observed for SiC@Au nanohybrids is due to our preparation process. As presented in Section 2.4, for the asprepared SiC@Au nanohybrids, two populations were identified: a first population that sedimented in few minutes and a second one that stayed in suspension for several days. Only the second population (in the supernatant) was kept for nonlinear optical measurements after 
natural sedimentation of the first one. Thus the concentration of $\mathrm{SiC}$ in $\mathrm{SiC} @ \mathrm{Au}$ nanohybrids is lower than the initial concentration in $\mathrm{SiC}$ suspension. This could explain the lower SHG signal. On the other hand, Au nanorods exhibit a non negligible signal between 420 and 610 nm, such as SiC@Au nanohybrids (Figure 3, insert). This signal increases with increasing detection wavelength, which proves that it is due to the TPL emission of Au nanorods. The low intensity peak detected at $455 \mathrm{~nm}$ for all samples is due to an artefact of the instrument. SiC@Au nanohybrids were then observed under multiphoton imaging (Figure 4).
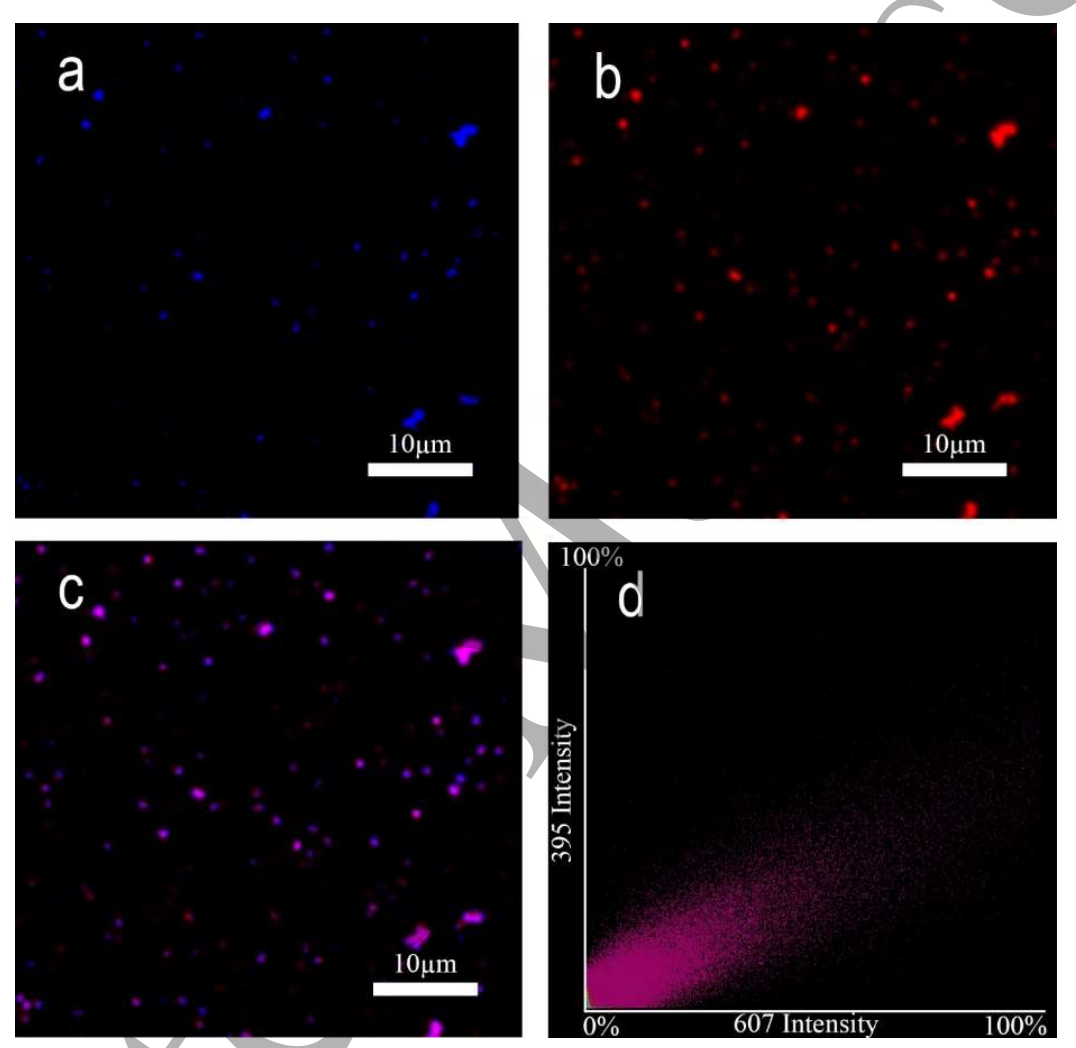

Figure 4. SiC@Au nanohybrids observed under multiphoton imaging (excitation wavelength: $790 \mathrm{~nm}$ ): detection at $395 \mathrm{~nm}$ (a), detection at $607 \mathrm{~nm}$ (b) and all detection channels overlayed (c). Colocalization plot between $395 \mathrm{~nm}$ and $607 \mathrm{~nm}$ detection channels (d).

As shown in Figures 4a and 4b, nanohybrids can be detected at both $395 \mathrm{~nm}$ and $607 \mathrm{~nm}$. The detection at $395 \mathrm{~nm}$ corresponds to the half of excitation wavelength thus to SHG signal from $\mathrm{SiC}$ nanoparticles while at $607 \mathrm{~nm}$, the TPL signal of Au nanorods is observed. These two 
signals appear to be co-localized in the same region, as shown in Figure 4c. This co-localization was quantified using an algorithm that counts the number of pixel intensities in the different channels and makes a correlation plot (Figure 4d). A Pearson's coefficient of 0.88 was obtained, which proves the strong cohesion of $\mathrm{SiC}$ with $\mathrm{Au}$ nanorods inside nanohybrids. By counting a total number of observed $\mathrm{SiC}$ nanoparticles and $\mathrm{SiC}$ nanoparticles colocalized with $607 \mathrm{~nm}$ channel we estimated that up to $90 \%$ of $\mathrm{SiC}$ nanoparticles were functionalized with gold nanorods. Next healthy cells were then incubated with SiC@Au nanohybrids and observed under multiphoton imaging (Figure 5).
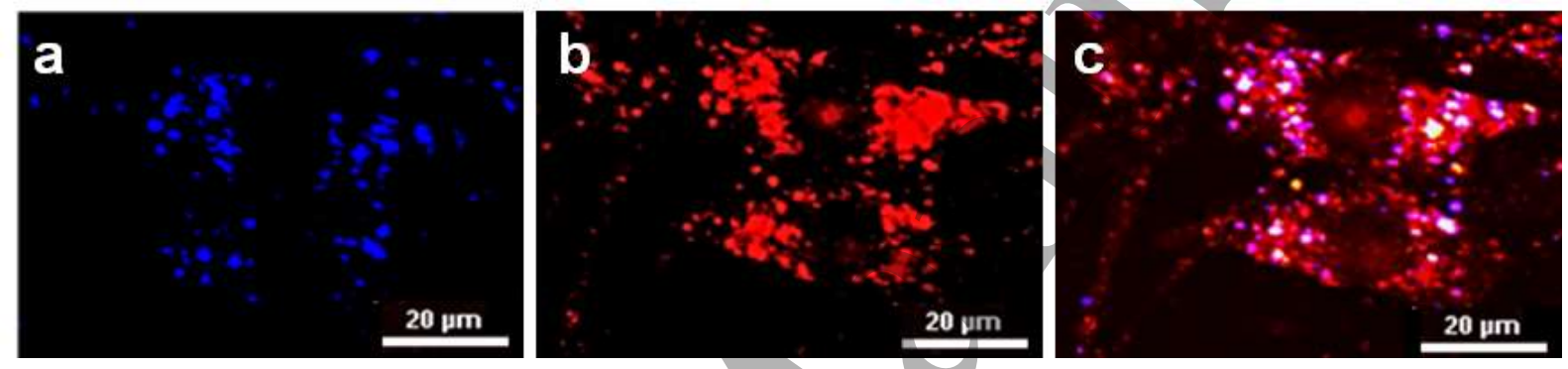

Figure 5.3T3-L1 healthy cells labelled with SiC@,Au nanohybrids observed under multiphoton imaging (excitation wavelength: $790 \mathrm{~nm}$ ): detection at $395 \mathrm{~nm}(\mathrm{a})$, detection at $607 \mathrm{~nm}$ (b) and all detection channels overlayed (c).

The signal detected at $395 \mathrm{~nm}$ (Figure 5a) corresponds to the SHG from SiC nanoparticles while the signal detected at $607 \mathrm{~nm}$ (Figure 5b) corresponds to the TPL of Au nanorods. To avoid the observation of cells autofluorescence, a low laser power was used. In this case, the autofluorescence signal is highly reduced and cannot be confused with the bright spots coming from nanoparticles and nanohybrids.

3.3. Photothermal properties of SiC@Au nanohybrids

Drops of nanoparticles and nanohybrids suspensions were directly irradiated using a $808 \mathrm{~nm}$ continuous-wave laser through an optical fiber. The power per surface unit emitted at the exit 
of the optical fiber was measured to be $40 \mathrm{~mW} \mathrm{~cm}^{-2}$. Instantaneously, heat generation was recorded with an infrared camera. The corresponding thermal images and temperature measurements are presented in Figure 6.

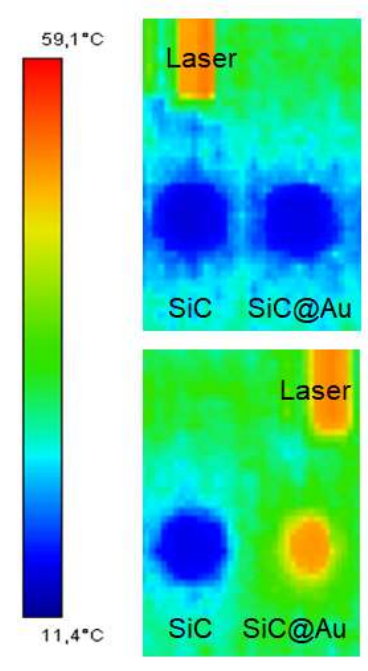

a

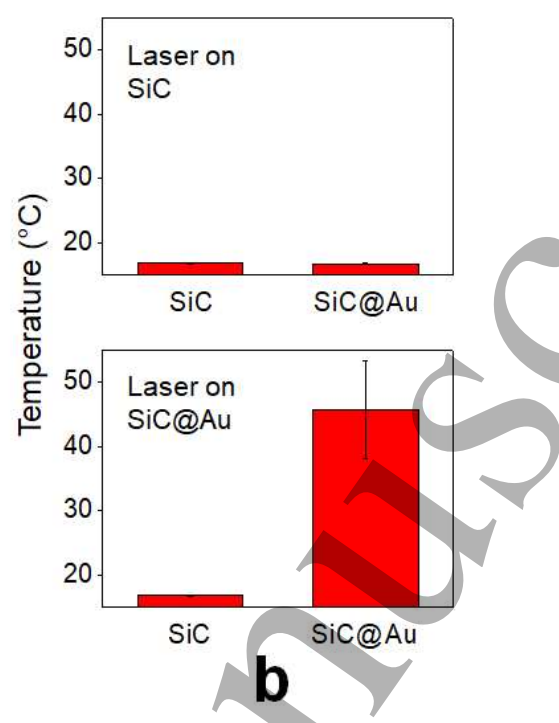

Figure 6. Thermal images (a) and corresponding temperatures (b) of drops of nanoparticles suspensions under $808 \mathrm{~nm}$ continuous-wave laser irradiation: SiC nanoparticles (left drop), and SiC@Au nanohybrids (right drop). The drop that is irradiated can be identified by the position of the laser optical fiber on each thermal image.

As shown in Figure 6, SiC nanoparticles irradiation did not lead to temperature increase while for SiC@Au nanohybrids, an instantaneous temperature elevation from $17^{\circ} \mathrm{C}$ to $45^{\circ} \mathrm{C}$ was obtained upon laser irradiation. A high temperature increase was also observed for Au nanorods dispersions (Figure S5, Supporting Information). Therefore, photothermal effect may be attributed to presence of Au nanorods into nanohybrids. As discussed in previous reviews, heat is mainly due to Joule effect generated by the current from oscillating electrons in the $\mathrm{Au}$ nanorod volume. ${ }^{[27,28]}$ However, surface effects can also appear due to the immersion of nanoparticles in a liquid, the presence of molecules (CTAB) at the surface of Au nanorods and their immobilization at the surface of a larger nanostructure ( $\mathrm{SiC}$ nanoparticles). As a 
consequence, surface thermal resistivity can occur and influence the heat release. Therefore, different Au nanorods coating may lead to different photothermal effects.

\subsection{Toxicity assay towards healthy cells}

Then, the toxicity of SiC nanoparticles and SiC@Au nanohybrids towards 3T3-L1 healthy cells was evaluated. The in-time evolution of cell index (proportional to the percentage of remaining living cells) was recorded using a non-destructive impedance-based method with an xCELLigence device (Figure 7). For a better comparison of the different samples, cell indices were normalized at the injection time $\mathrm{t}_{0}$ of nanoparticles $(48 \mathrm{~h}$ after the beginning of cell culture).

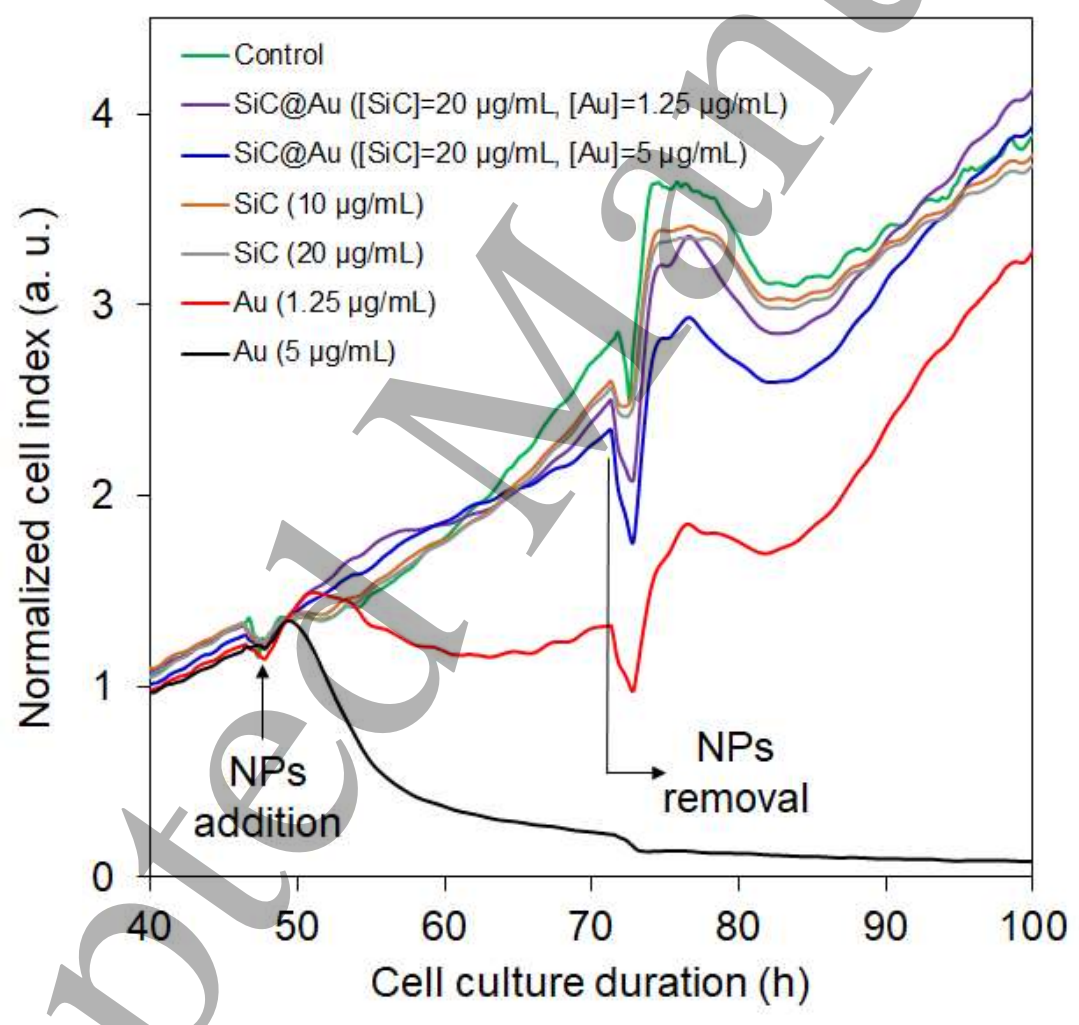

Figure 7. Normalized cell index measured by xCELLigence system as a function of cell culture duration for 3T3-L1 healthy cells in presence of SiC, SiC@Au and Au nanorods at various concentrations. Control samples correspond to 3T3-L1 healthy cells only. Nanoparticles were added at $\mathrm{t}_{0}=48 \mathrm{~h}$ after the beginning of cell culture and removed at $72 \mathrm{~h}\left(\mathrm{t}_{0}+24 \mathrm{~h}\right)$. 
As shown in Figure 7, $\mathrm{SiC}$ nanoparticles of concentrations ranging from 10 to $20 \mu \mathrm{g} / \mathrm{mL}$ did not interfer with cell proliferation. This is in agreement with previous work ${ }^{[29]}$ in which $\mathrm{SiC}$ nanoparticles with a diameter larger than $15 \mathrm{~nm}$ did not exhibit cytotoxic effect. Besides, their highly negative zeta potential (lower than $-40 \mathrm{mV}$, Figure S2) did not favor the uptake of these large diameter nanoparticles by cells ${ }^{[30-32]}$. On the contrary, Au nanorods exhibited a high toxicity for 3T3-L1 healthy cells, with a cytostatic effect for a concentration of $1.25 \mu \mathrm{g} / \mathrm{mL}$ and a clear cytotoxic effect for a concentration of $5 \mu \mathrm{g} / \mathrm{mL}$ although Au nanorods are known to be biocompatible in a broad range of aspect ratios from 2.2 to $5.9 .{ }^{[33]}$ However, their surface chemistry also have a great importance on their cytotoxicity. ${ }^{[34]}$ In particular, the presence of $\mathrm{CTAB}$ onto Au nanorods surface may be related to their observed high toxicity. ${ }^{[35]}$ Indeed, CTAB induces a positive surface charge (Figure S2, Supporting Information) resulting to an increased cellular uptake, which can lead to intracellular toxicity. A previous study also showed that toxicity of Au nanorods was mainly due to free CTAB residues issued from desorption ${ }^{[36]}$. SiC@Au nanohybrids were prepared according to the protocol detailed in Section 2.4 using the lowest $(1.25 \mu \mathrm{g} / \mathrm{mL})$ and the highest $(5 \mu \mathrm{g} / \mathrm{mL})$ concentrations of Au nanorods. Although it was difficult to determine the amount of $\mathrm{Au}$ nanorods really immobilized onto $\mathrm{SiC}$ nanoparticles surface, the two kinds of SiC@Au nanohybrids were found to be non toxic. Thus the concentration of free Au nanorods after washing of SiC@Au nanohybrids was supposed to be negligible, even when using the highest $\mathrm{Au}$ nanorods concentration for their preparation. The toxic effect of CTAB might be reduced in SiC@Au nanohybrids compared to Au nanorods because of the screening effect of $\mathrm{SiC}$ nanoparticles. Attempts to exchange CTAB by other ligands were carried out but lead to poor colloidal stability. Besides, Au nanorods linked to larger diameter SiC nanoparticles $(150 \mathrm{~nm})$ may behave like high diameter spherical nanoparticles that are too big to be internalized by endocytosis. It was shown that above $50 \mathrm{~nm}$ in diameter, the capacity of a nanoparticle to be submitted to endocytosis decreases and 
becomes negligible above $100 \mathrm{~nm} \cdot{ }^{[37]}$ Such results are in agreement with the observation of 3T3-L1 cells labelled with $\mathrm{SiC}$ nanoparticles and $\mathrm{Au}$ nanorods (Figure S3, Supporting Information) showing that $\mathrm{SiC}$ nanoparticles were more located on the periphery of cells while Au nanorods are more homogeneously distributed onto cells and are able to penetrate inside.

\subsection{Phototherapeutic properties}

Finally, nanoparticles and nanohybrids were incubated with cancer cells and their toxicity was compared with and without continuous-wave laser irradiation at $808 \mathrm{~nm}\left(40 \mathrm{~mW} \mathrm{~cm} \mathrm{~cm}^{-2}\right)$, which corresponds to the spectral region where Au nanorods strongly absorbs light and thus can lead to photothermal effect. In order to evaluate this effect, the in-time eyolution of cell index (proportional to the percentage of remaining living cells) was recorded. For a better comparison of the different samples, cell indices were normalized at the injection time $t_{0}$ of nanoparticles (92 $\mathrm{h}$ after the beginning of cell culture). The evolution curves for $\mathrm{SiC}$ nanoparticles and SiC@Au nanoparticles and nanohybrids are shown in Figure 8a. The percentage of remaining living cells at different stages of the experiment extracted from these curves is presented in Figure $8 b$.
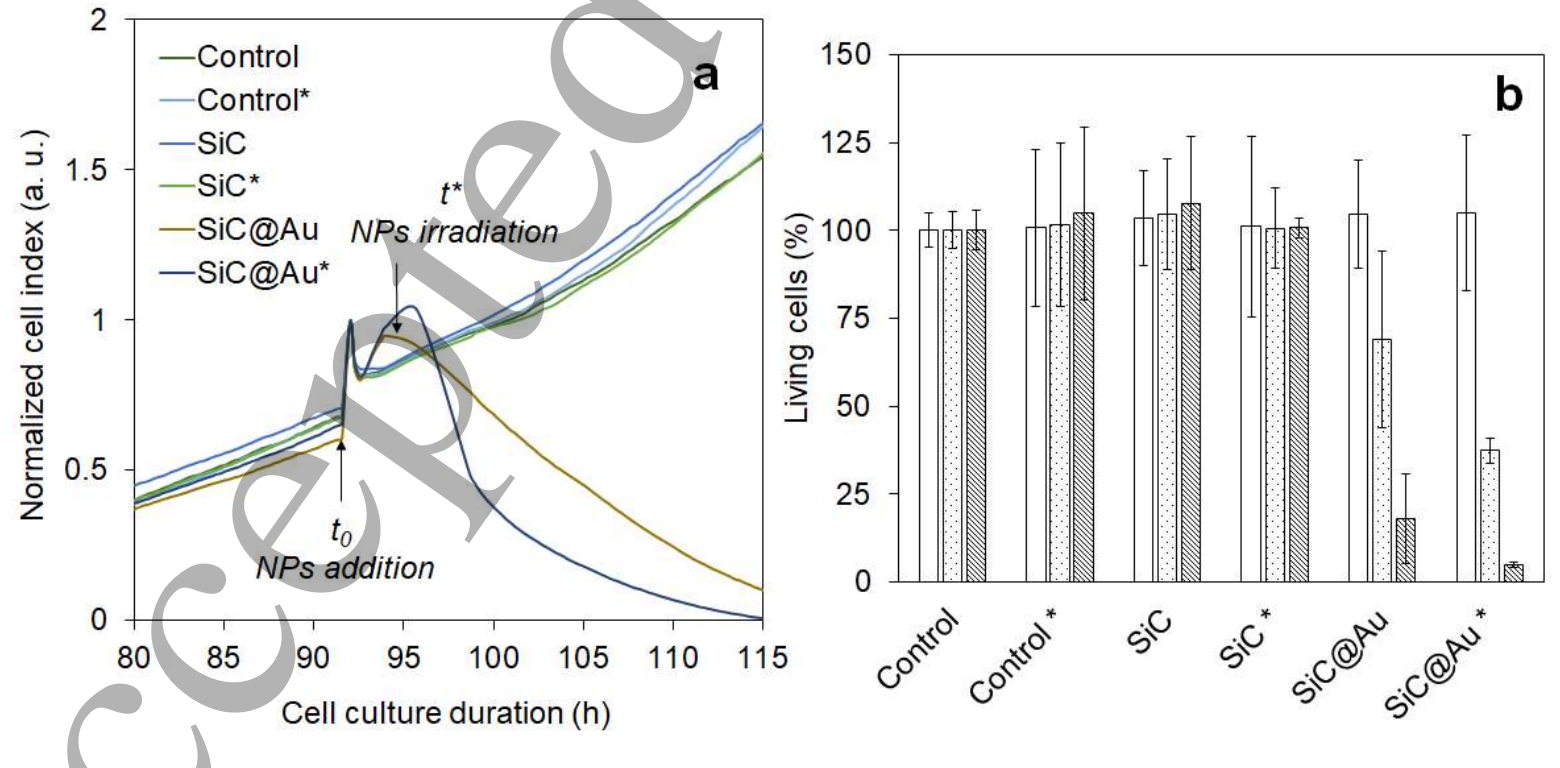
Figure 8. (a) Normalized cell index measured by xCelligence system as a function of cell culture duration for $\mathrm{HuH7}$ cancer cells in presence of $\mathrm{SiC}$ nanoparticles and $\mathrm{SiC} @ \mathrm{Au}$ nanohybrids. Control samples correspond to $\mathrm{HuH7}$ cells only. Nanoparticles were added at $\mathrm{t}_{0}=$ $92 \mathrm{~h}$ after the beginning of cell culture. The irradiation (samples labelled with a *) was performed at $\mathrm{t}^{*}=94 \mathrm{~h}$ for $6 \mathrm{~min}$. (b) Percentage of remaining living $\mathrm{HuH} 7$ cancer cells at $\mathrm{t}_{0}+$ $1 \mathrm{~h}$ (white bars), $\mathrm{t}^{*}+6 \mathrm{~h}$ (dot bars) and $\mathrm{t}^{*}+16 \mathrm{~h}$ (stripe bars).

As shown in Figure 8a, HuH7cells only or $\mathrm{HuH} 7$ cells in presence of SiC nanoparticles were still proliferating with or without laser irradiation. However, the presence of nanohybrids produced a significant decrease of cancer cells proliferation, even without laser irradiation. This effect was more pronounced for SiC@Au under laser irradiation: 6 hours after nanoparticles irradiation, the rate of living cells was around 70\% for non-irradiated SiC@Au while it was of 37\% for irradiated SiC@Au (Figure 8b). These rates fell to 18\% for non-irradiated SiC@Au and 5\% for irradiated SiC@Au 16 h after nanoparticles irradiation. Besides, as shown in Figure 8a, nanohybrids injection into cancer cells was accompanied by an increase of normalized cell index from $\mathrm{t}=92.5 \mathrm{~h}$ to $\mathrm{t}=95 \mathrm{~h}$, which was not observed for control sample, SiC nanoparticles. This could be attributed to an increase of cell volume, which may be due to cellular necrosis that is often preceded with a phase of cellular swelling prior to cellular lysis. As discussed in Section 3.4, such a behavior implies the probable presence of free Au nanorods in the samples. Although SiC@Au nanohybrids were found to be non toxic for 3T3-L1 healthy cells (Figure 7), a different behavior was observed in the presence of $\mathrm{HuH7}$ cancer cells. Indeed, it was demonstrated that the exposure of different cell types to the same kind of nanoparticles may influence cell morphology, ATP and ROS production and their capacity of cellular uptake ${ }^{[38-}$ ${ }^{41]}$. Besides, concerning in vivo studies, it is also well known that nanoparticles may be more efficiently accumulated by tumor tissue than by healthy one due to enhanced penetration and 
retention (EPR) effect ${ }^{[42]}$. This can potentially induces the penetration of some free Au nanorods inside $\mathrm{HuH} 7$ cells, leading to toxicity. However, the higher toxicity observed after of irradiation may due to the photothermal effect of nanohybrids, without excluding the possible presence of free Au nanorods inside the cells, as discussed before.

\section{Conclusions}

In this study, nanohybrids were prepared from harmonic nanoparticles coated with gold nanorods. Their structural and nonlinear optical properties were investigated, showing that the two kinds of nanoparticles were colocalized. Photothermal effect was measured. Harmonic nanoparticles and nanohybrids showed no effect on cell proliferation as assessed by impedance measurements cytotoxicity for healthy cells while gold nanorods were found to exhibit a dose dependent toxicity. However, this effect may not be related to gold nanorods by theirselves but to $\mathrm{CTAB}$ coated on their surface. Finally, the phototherapeutical properties of nanohybrids upon cancer cells were studied. Without laser irradiation, nanohybrids exhibit toxicity for cancer cells. This effect is increased under laser irradiation. This work can provide several opportunities in the field of cell imaging and cancer therapy. The measurement of two distinct nonlinear optical signals for the two components (SHG for harmonic nanoparticles and TPL for gold nanorods) offers the possibility of multiplexed detection. This could bring more accuracy for the detection of cancer cells. Furthermore, thanks to the NIR transparency window and the spatial resolution of $\mathrm{SHG}$, one can expect to be able to gain 3D information on the morphology of tumoral tissue. The elaborated nanohybrids also have the potential to affect cancer cells while preserving healthy cells. Although the photothermal effect is probably not the only process involved, this represents interesting perspectives in the cancer nanotherapy research field.

\section{Acknowledgements}


This work was supported by LABEX iMUST (ANR-10-LABX-0064) of Lyon University, as part of the "Investissements d'Avenir" program (ANR-11-IDEX-0007) of the French National Research Agency (ANR). This work was also supported by ANR in the frame of RACINE project (ANR-17-CE24-0029-03). The European Union INTERREG V France-Suisse program (NANOFIMT project) is also acknowledged for financial support. V. M. and L. B. acknowledge PHC Germaine de Staël 2015 for the funding of experimental campaigns. A. Rogov and C. Schmidt are acknowledged for their participation to data acquisition. G. Chareyre is acknowledged for his help with the implementation of photothermal experiments.

\section{References}

[1] World Health Organization, "Cancer," can be found under http://www.who.int/newsroom/fact-sheets/detail/cancer, 2018.

[2] J. A. Webb, R. Bardhan, Nanoscale 2014, 6, 2502.

[3] D. P. O’Neal, L. R. Hirsch, N. J. Halas, J. D. Payne, J. L. West, Cancer Lett. 2004, 209, 171.

[4] V. P. Zharov, E. N. Galitovskaya, C. Johnson, T. Kelly, Lasers Surg. Med. 2005, 37, 219.

[5] C. M. Pitsillides, E. K. Joe, X. Wei, R. R. Anderson, C. P. Lin, Biophys. J. 2003, 84, 4023.

[6] B. Khlebtsov, V. Zharov, A. Melnikov, V. Tuchin, N. Khlebtsov, Nanotechnology 2006, 17,5167 .

[7] P. K. Jain, K. S. Lee, I. H. El-Sayed, M. A. El-Sayed, J. Phys. Chem. B 2006, 110, 7238.

[8] G. N. Abdelrasoul, R. Magrassi, S. Dante, M. d'Amora, M. S. d'Abbusco, T. Pellegrino, A. Diaspro, Nanotechnology 2016, 27, 255101. 
[9] Y. Zhang, J. Yu, D. J. S. Birch, Y. Chen, J. Biomed. Opt. 2018, 15, 020504.

[10] R. K. P. Benninger, D. W. Piston, Two-Photon Excitation Microscopy for the Study of Living Cells and Tissues, Curr. Protoc. Cell. Biol., Chapter 4, 2013.

[11] L. Bonacina, Mol. Pharm. 2013, 10, 783.

[12] L. Dubreil, I. Leroux, M. Ledevin, C. Schleder, L. Lagalice, C. Lovo, R. Fleurisson, S. Passemard, V. Kilin, S. Gerber-Lemaire, M.-A. Colle, L. Bonacina, K, Rouger, ACS Nano 2017, 7, 6672.

[13] D. Staedler, T. Magouroux, R. Hadji, C. Joulaud, J/Extermann, S. Schwung, S. Passemard, C. Kasparian, G. Clarke, M. Gerrmann, R. Le Dantec, Y. Mugnier, D. Rytz, D. Ciepielewski, C. Galez, S. Gerber-Lemaire, L. Juillerat-Jeanneret, L. Bonacina, J. P. Wolf, ACS Nano 2012, 6, 2542.

[14] M. Boksebeld, V. Kilin, A. Geloën, G. Ceccone, A. Jaffal, C. Schmidt, S. Alekseev, V. Lysenko, J. P. Wolf, L. Bonacina, E. Souteyrand, Y. Chevolot, V. Monnier, RSC Adv. 2017, 7, 27361.

[15] E. Redolfi Riva, I. Pastoriza-Santos, A. Lak, T. Pellegrino, J. Pérez-Juste, V. Mattoli, J. Colloid Interface Sci. 2017, 502, 201.

[16] D.-W. Wang, X.-M. Zhu, S.-F. Lee, H.-M. Chan, H.-W. Li, S. K. Kong, J. C. Yu, C. H. K. Cheng, Y.-X. J. Wang, K. C.-F. Leung, J. Mater. Chem. B 2013, 1, 2934.

[17] Y. Hu, Y. Zhou, N. Zhao, F. Liu, F. J. Xu, Small 2016, 12, 2459.

[18] M.H. Chan, S. P. Chen, C. W. Chen, Y. C. Chan, R. J. Lin, D. P. Tsai, M. Hsiao, R. J. Chung, X. Chen, R. S. Liu, J. Phys. Chem. C 2018, 122, 2402.

[19] C.-W. Chen, P.-H. Lee, Y.-C. Chan, M. Hsiao, C.-H. Chen, P. C. Wu, P. R. Wu, D. P. 
Tsai, D. Tu, X. Chen, R.-S. Liu, J. Mater. Chem. B 2015, 3, 8293.

[20] Q. Sun, Q. You, X. Pang, X. Tan, J. Wang, L. Liu, F. Guo, F. Tan, N. Li, Biomaterials 2017, 122, 188 .

[21] A. K. Parchur, Q. Li, A. Zhou, Biomater. Sci. 2016, 4, 1781.

[22] Y. Hu, C. Wen, L. Song, N. Zhao, F. J. Xu, J. Control. Release 2017, 255, 154.

[23] B. Nikoobakht, M. A. El-Sayed, Chem. Mater. 2003, 15, 1957.

[24] M. Boksebeld, N. P. Blanchard, A. Jaffal, Y. Chevolot, V. Monnier, Gold Bull. 2017, $50,69$.

[25] S. Link, M. B. Mohamed, M. A. El-Sayed, J. Phys. Chem. B 1999, 103, 3073.

[26] A. Brioude, X. C. Jiang, M. P. Pileni, J. Phys. Chem. B 2005, 109, 13138.

[27] G. Baffou, R. Quidant, C. Girard, Phys. Rev. B 2010, 82, 165424.

[28] G. Baffou, R. Quidant, Laser Photonics Rev. 2013, 7, 171.

[29] J. Pourchez, D. Boudard, V. Forest, N. Boumahdi, M. Tomatis, B. Fubini, B. Guilhot, M. Cottier, P. Grosseau, J. Nanopart. Res. 2014, 14, 1143.

[30] C. M. Goodman, C. D. McCusker, T. Yilmaz, V. M. Rotello, Bioconjugate Chem. 2004, $15,897$.

[31] H. Hillaireau, P. Couvreur, Cell. Mol. Life Sci. 2009, 66, 2873.

[32] A. M. Alkilany, P. K. Nagaria, C. R. Hexel, T. J. Shaw, C. J. Murphy, M. D. Wyatt, Small 2009, 5, 701.

[33] X. Huang, S. Neretina, M. A. El-Sayed, Adv. Mater. 2009, 21, 4880.

[34] S. Sultana, N. Djaker, S. Boca-Farcau, M. Salerno, N. Charnaux, S. Astilean, H. 
Hlawaty, M. L. De La Chapelle, Nanotechnology 2015, 26, 55101.

[35] E. E. Connor, J. Mwamuka, A. Gole, C. J. Murphy, M. D. Wyatt, Small 2005, 1, 325.

[36] I. P. Lau, H. Chen, J. Wang, H. C. Ong, K. C. F. Leung, H. P. Ho, S. K. Kong, Nanotoxicology 2012, 6, 847.

[37] B. D. Chithrani, A. A. Ghazani, W. C. W. Chan, Nano Lett. 2006, 6, 662.

[38] C. Hanley, A. Thurber, C. Hanna, A. Punnoose, J. Zhang, D. G. Wingett, Nanoscale Res. Lett. 2009, 4, 1409.

[39] W. Busch, S. Bastian, U. Trahorsch, M. Iwe, D. Kühnel, T. Meiner, A. Springer, M. Gelinsky, V. Richter, C. Ikonomidou, A. Potthoff, I. Lehmann, K. Schirmer, J. Nanoparticle Res. 2011, 13, 293.

[40] F. Joris, D. Valdeperez, B. Pelaz, S. J. Soenen, B. B. Manshian, W. J. Parak, S. C. De Smedt, K. Raemdonck, J. Nanobiotechnology 2016, 14, 1.

[41] X. Xie, J. Liao, X. Shao, Q. Li, Y. Lin, Sci. Rep. 2017, 7, 1.

[42] J. L. Perry, K. G. Reuter, J. C. Luft, C. V. Pecot, W. Zamboni, J. M. DeSimone, Nano Lett. 2017, 17, 2879. 